\title{
Collapse mechanism of cut-and-cover tunnels under seismic loading
}

\author{
Duhee Park ${ }^{\text {i) }}$ Tae-Hyung Lee ${ }^{\text {ii)}}$, Duy Duan Nguyen ${ }^{\text {iii) }}$ and Jeongseon Park ${ }^{\text {iv }}$
}

\begin{abstract}
i) Associate professor, Department of Civil and Environmental Engineering, Hanyang University, 506 Jaesung Civil Engr Bldg, Wansimni-ro, Sungdong-gu, Seoul, 133-791, Korea.

ii) Associate professor, Department of Civil and Environmental Engineering, Konkuk University, Korea.

iii) Ph.D. student, Department of Civil and Environmental Engineering, Konkuk University, Korea.

iv) Ph.D. student, Department of Civil and Environmental Engineering, Hanyang University, Korea.
\end{abstract}

\begin{abstract}
We investigate the collapse mechanism of rectangular cut-and-cover tunnels under seismic loading from inelastic frame analyses. The propagation of plastic hinges in the reinforced concrete lining is observed. It is shown that the plastic hinge start to form at the bottom corners of the structure. The shear strain at which the plastic hinge start to develop and tunnel collapses are investigated. Whereas the plastic hinge develops at a shear strain of $1.2 \%$ for soils with a shear velocity of $50 \mathrm{~m} / \mathrm{s}$, it is formed at a low shear strain of $0.04 \%$ for a soil with a shear velocity of $400 \mathrm{~m} / \mathrm{s}$. The shear strain - moment diagram proposed in this study provide a simple yet robust method to evaluate the seismic performance of cut-and-cover box tunnels under seismic loading.
\end{abstract}

Keywords: collapse mechanism, damage state, cut-and-cover tunnel, seismic loading, inelastic frame analysis

\section{INTRODUCTION}

The construction of metro systems in large urban areas is important for the socioeconomic development of a modern country. The underground space plays important roles in the transportation network of a city. In general, underground structures were shown to suffer less damage than aboveground structures during seismic events. However, in recent strong earthquakes, it was demonstrated that even underground structures can be vulnerable under strong seismic excitations, including the 1999 Chi-Chi, Taiwan earthquake, the 2004 Mid Niigata Prefecture, Japan earthquake and the 2008 Wenchuan, China earthquake (Wang and Zhang, 2013; Hashash et al., 2001). Therefore, we need to design underground structures to be resistant to strong ground motions.

Underground structures embedded in soil layers or rock are primarily subjected to the deformation of the surrounding ground, therefore their behavior has distinct differences compared to superstructures under an earthquake event (Wood, 2004). Even though the tunnel is expected to undergo inelastic behavior under severe earthquake event, previous studies assumed that the tunnel behaves linear elastically even close to collapse (Wang, 1993; Hashash et al., 2001; Argyroudis and Pitilakis, 2012). Fragility curves of rectangular structures have been proposed, assuming the linear elastic response of tunnels (Argyroudis and Pitilakis, 2012; Androtti and Martinelli, 2013). However, the accuracy of such an assumption has not been thoroughly investigated.

We investigate the non-linear behavior of rectangular cut-and-cover tunnels under seismic loading from inelastic reinforced concrete frame analysis. The deformation of the ground is imposed to the springs connected to the tunnel frame as displacement boundary conditions. We also applied shear stress induced by the deformation of the ground to the tunnel structural elements. Reponse of the tunnel from elastic to inelastic range and the development and propagation of plastic hinges are observed. Based on the analysis results, representative shear strain ranges at which the plastic hinges develop are identified.

\section{NUMERICAL SIMULATION}

The cut-and-cover used in the numerical simulation is shown in Fig. 1. It is a single barrel type of tunnel with a soil cover of $7 \mathrm{~m}$. The structural details of the tunnel are shown in Fig. 2. The elastic modulus $\left(E_{c}\right)$ and shear modulus $\left(\mathrm{G}_{\mathrm{c}}\right)$ of concrete are $2.48 \times 10^{7}$ $\mathrm{KN} / \mathrm{m}^{2}$ and $1.03 \times 10^{7} \mathrm{KN} / \mathrm{m}^{2}$, respectively, while for steel are $2 \times 10^{8} \mathrm{KN} / \mathrm{m}^{2}$ and $7.7 \times 10^{7} \mathrm{KN} / \mathrm{m}^{2}$, respectively. The specified concrete compressive strength $\left(\mathrm{f}_{\mathrm{c}}{ }^{\prime}\right)$ is $2.75 \times 10^{4} \mathrm{KN} / \mathrm{m}^{2}$, while the yield stress $\left(\mathrm{f}_{\mathrm{y}}\right)$ of longitudinal steel is $4.13 \times 10^{5} \mathrm{KN} / \mathrm{m}^{2}$. Nonlinear models were used for the concrete and reinforced steel bars, as shown in Fig. 3. Moment-curvature relationships of 
section A using section analysis is shown in Fig. 4.

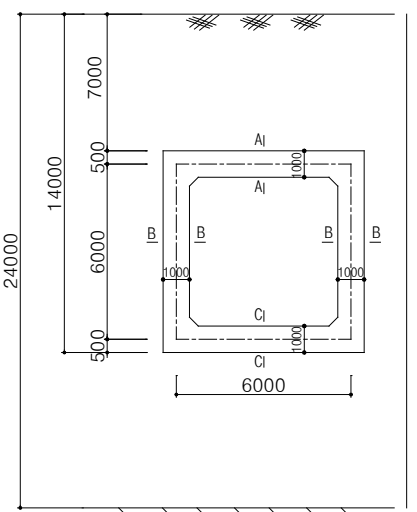

Fig. 1. Soil profile and tunnel dimensions

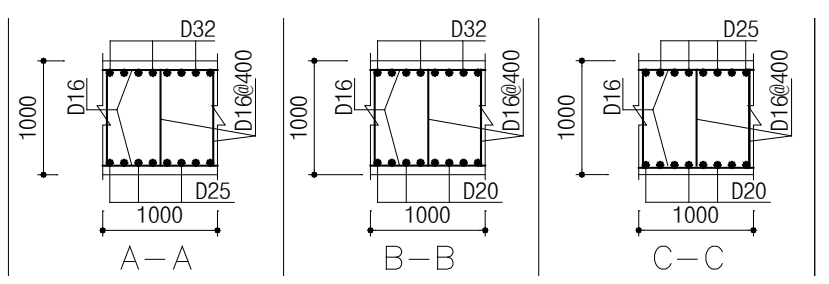

Fig. 2. Sectional details of the tunnel
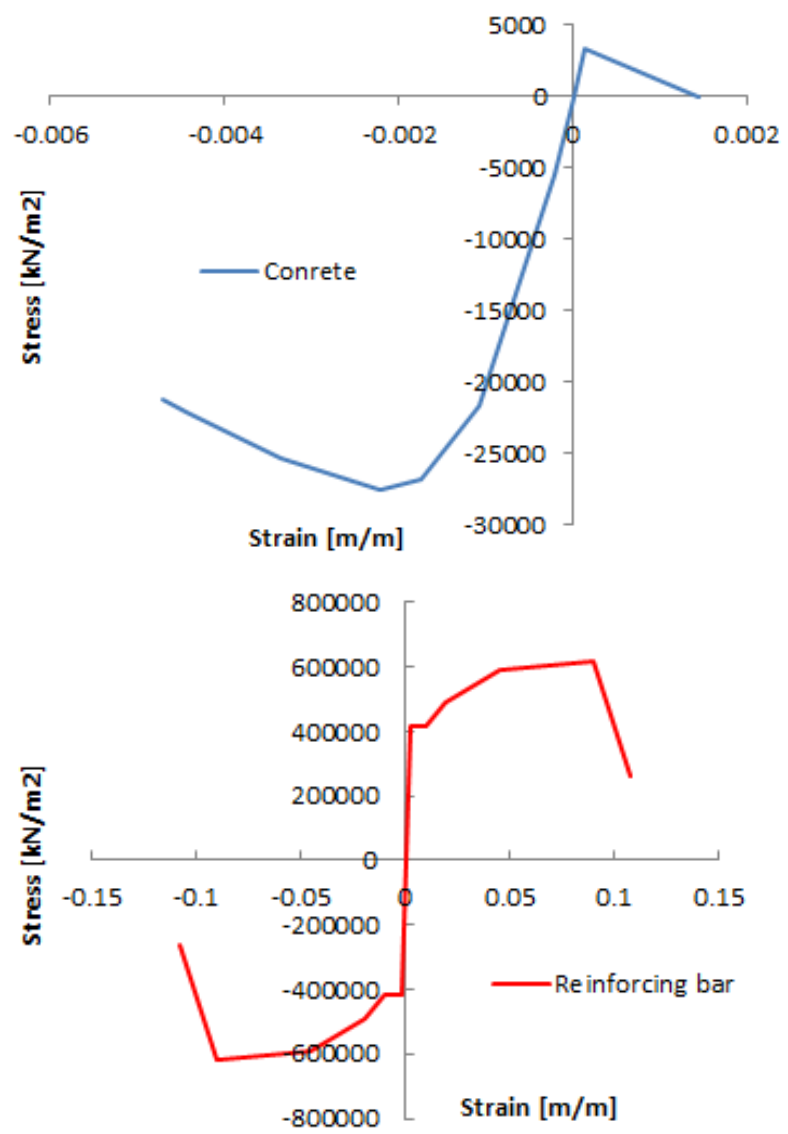

Fig. 3. Numerical models for concrete and reinforced stee

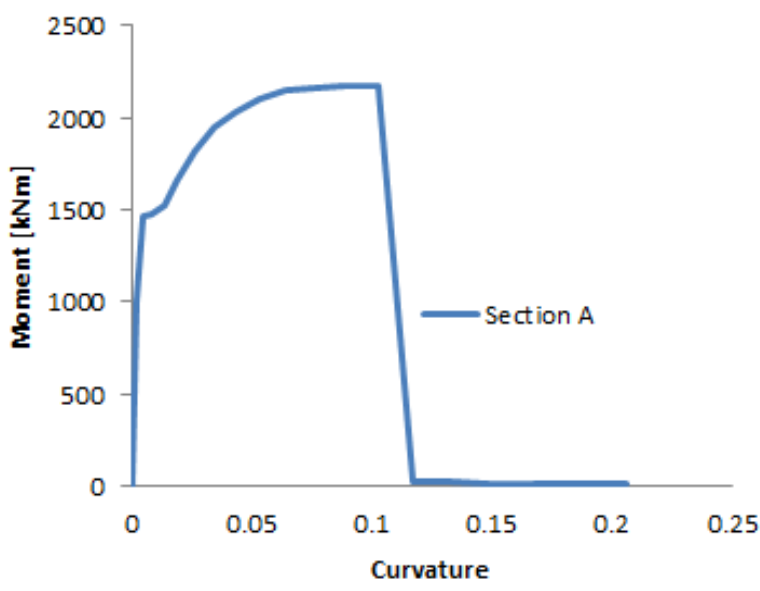

Fig. 4. Moment-curvature curve of section A-A

Numerical simulation of whole structures is conducted by the SAP2000 software. The schematic plot of the tunnel frame model and applied geo-static forces and seismically induced displacement is shown in Fig. 5. Each structural element of the models is divided into 64 small elements and the offsets at the corners of tunnels are also considered in the procedure. The frame hinge type for the concrete beam is applied at all elements (FEMA 356, 2000). This implementation indicates that plastic hinges can be occur anywhere in the frame elements of the structures.

The coefficient of horizontal and vertical subgrade reactions are respectively defined as $K_{H}=k_{h 0}\left(\frac{h}{30}\right)^{-3 / 4}$ and $K_{V}=k_{h 0}\left(\frac{b}{30}\right)^{-3 / 4}$ where $k_{h 0}=\left(\frac{1}{30}\right) E_{D}, h$ and $b$ are respectively the height and the width of the tunnel wall, $E_{D}$ is dynamic elastic modulus $E_{D}=2\left(1+v_{\mathrm{D}}\right) G_{D}$, $v_{D}$ is dynamic Poisson's ratio of soil, $G_{D}$ is dynamic shear modulus calculated as $G_{D}=\left(\gamma_{t} / g\right) E_{B}^{2}, \gamma_{t}$ is the density of soil, $V_{s}$ is the shear velocity of surrounding soil and $g$ is the gravitational acceleration.

We performed push over analyses until the tunnel reaches failure. The schematic plot of the analysis is shown in Fig. 5. Five shear wave velocities were used to investigate the effect of the stiffness of the soil. Firstly, the geostatic stresses were applied to the vertical and lateral boundaries. We assumed that the coefficient of lateral earth pressure $\left(K_{o}\right)$ as 1.0. Secondly, we applied displacement to the springs at the lateral boundaries and also to the shear springs at the top of the slab. We also applied shear stresses directly to the structural elements. The development of plastic hinges within the tunnel strutual elements were observed and the moment and base forces were calculated. 


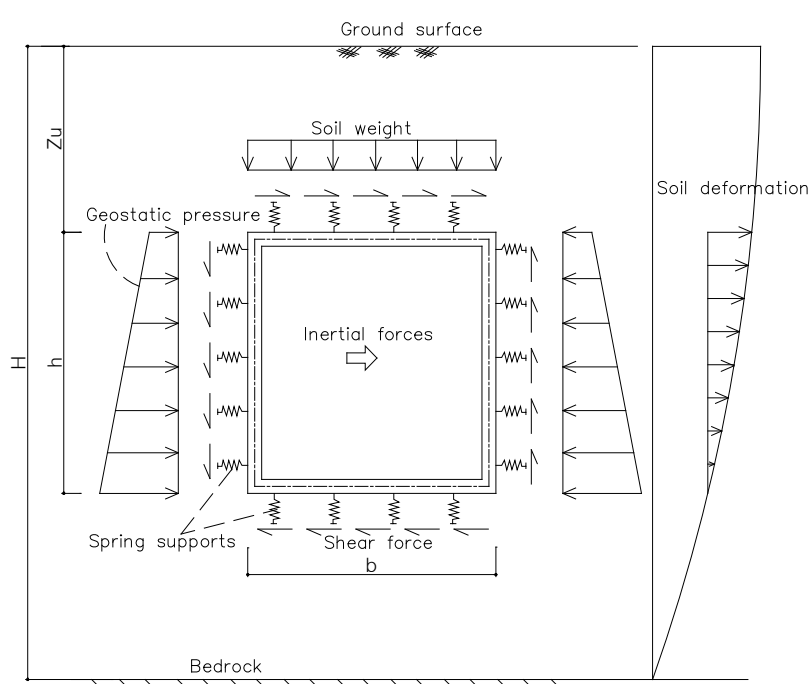

Fig. 5. Schematic representation of the tunnel frame model and applied geostatic forces and seismically induced displacement

\section{RESULTS OF SIMULATION}

Fig. 6. shows the results of the pushover analysis. The Base shear force is plotted against the top horizontal displacement for single barrel rectangular structures in soils ranging in shear wave velocities from $50 \mathrm{~m} / \mathrm{s}$ to $400 \mathrm{~m} / \mathrm{s}$.. The base shear is significantly lower for low shear velocity soils, demonstrating that the force required to push the structure into failure is lower for softer soils. Fig. 7. shows the moments calculated in the structural elements with respect to induced shear strain in the ground. It is shown that the induced moment of the structural element increases with increasing the shear wave velocity of the soil, which is obvious because the lateral force induced by the soil increases if the shear wave velocity of the soil increases. The shear strain at which the plastic hinges form depends on the stiffness of the soil. However, unlike the base shear, the moment at which respective plastic hinges form is quite similar.

The sequences and the positions of the plastic hinges of the single box are illustrated in Fig. 8 - 9. The relative displacement shown in the figure is the difference in the horizontal displacement between the top and bottom slabs divided by the height of the tunnel. It is equivalent to the induced shear strain in the soil. The first plastic hinge develops at the left bottom corner, followed by the right bottom corner. Third hinge develops at the right top corner, positioned diagonally from the first plastic hinge. The fourth and final plastic hinge develops at the top left corner. It is shown that the bottom corner is more susceptible to seismic damage than the top corners. When the shear velocity is 50 $\mathrm{m} / \mathrm{sec}$, first plastic hinge is formed at a high shear strain of $1.2 \%$. The tunnel collapses when the shear strain is as high as $2.5 \%$. It is demonstrated that a very high level of shear strain is needed to cause collapse of the single barrel box tunnel. Fig. 8. shows the sequence of plastic hinges and corerspondig relative displacements for a box tunnel in a soil with $\mathrm{Vs}=400 \mathrm{~m} / \mathrm{s}$. The sequence of plastic hinges that develop within the structure is different from the case of $\mathrm{Vs}=50 \mathrm{~m} / \mathrm{s}$. After the first hinge develops in the left bottom corner, the second hinge is formed at the top right corner. Third and fourth hinges develop at the right bottom and top left corners, respectively. Also to be noted is the very low levels of shear strains at which the plastic hinges are formed. The first hinge develops at a low shear strain amplitude of $0.04 \%$. The tunnel collapses at a shear strain of $0.12 \%$. The calculations highlight that a severe structural damage will be induced in a box tunnel at very low levels of shear strain.

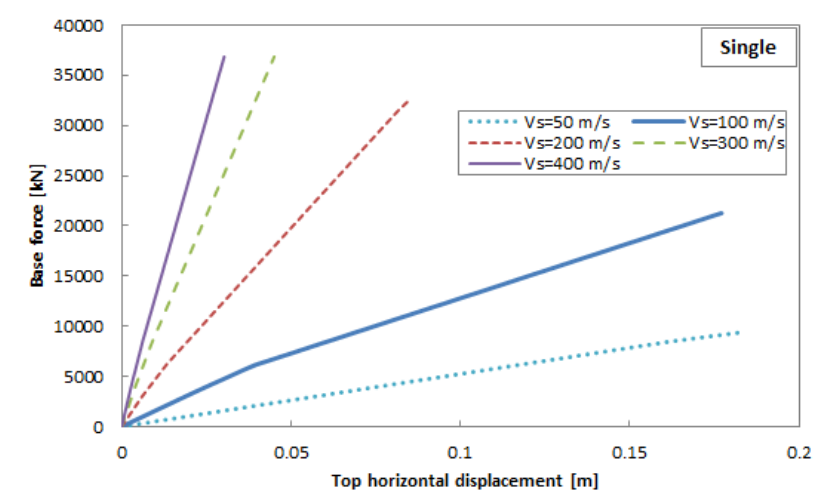

Fig. 6. Pushover curves fo the single barrel tunnel

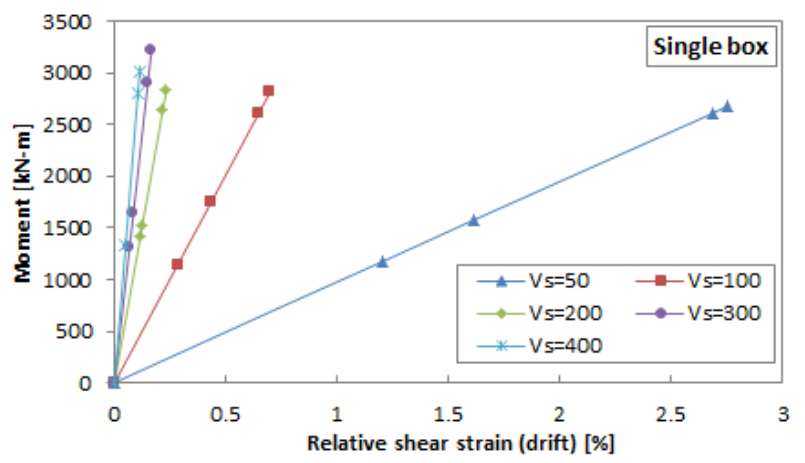

Fig. 7. Moment versus relative shear strain (\%) relationship at the formation of plastic hinges (shown as filled dots)

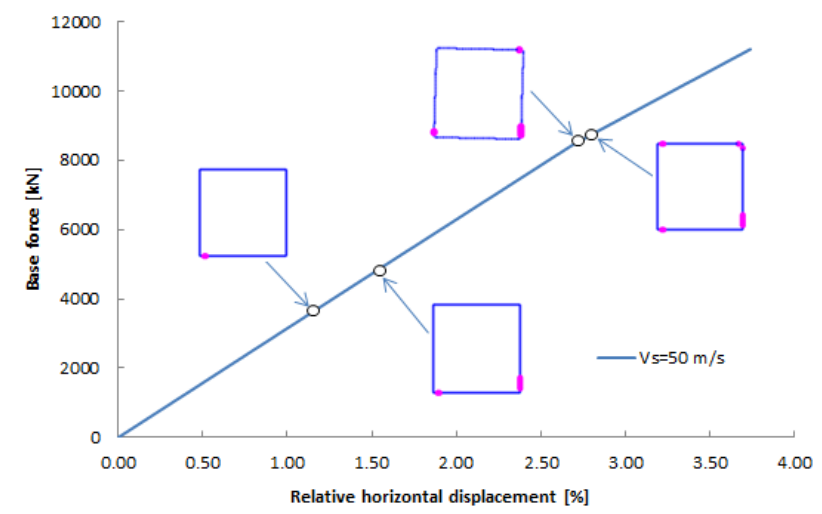

Fig. 8. Sequence of plastic hinges that develops in a single barrel box tunnel $(\mathrm{Vs}=50 \mathrm{~m} / \mathrm{s})$ 


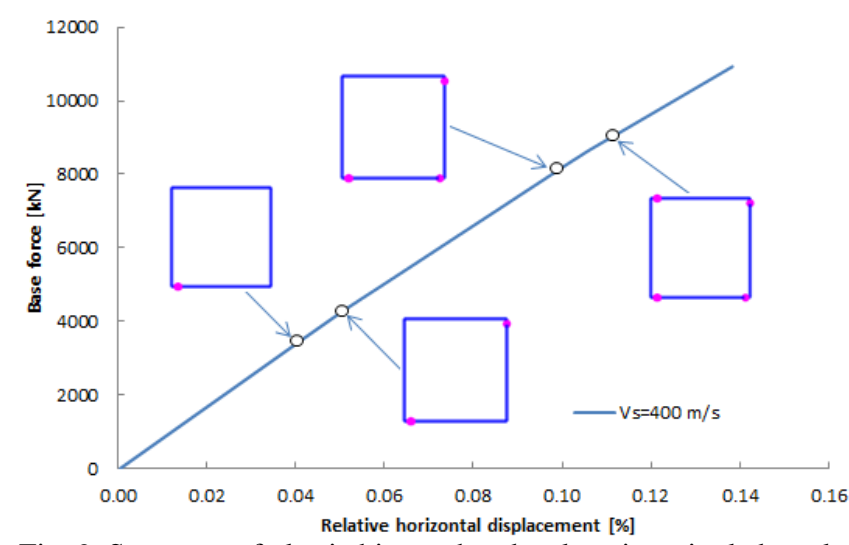

Fig. 9. Sequence of plastic hinges that develops in a single barrel box tunnel $(\mathrm{Vs}=400 \mathrm{~m} / \mathrm{s})$

\section{CONCLUSIONS}

A series of 2D inelastic frame analyses were performed to identify the collapse mechanism of frame tunnels under seismic loading. The dynamic response of box tunnels was represented via a pseudo-static analysis where the free-field deformation was imposed as displacement boundaries and shear stresses to the springs attached to the tunnel structure. The pattern of propagation of plastic hinges in the reinforced concrete lining was observed. It is shown that the plastic hinge start to form at the bottom corners of the structure. The shear strain at which the tunnel collapses are dependent of the shear wave velocity of the soil. Whereas the plastic hinge develops at a shear strain of $1.2 \%$ for soils with a shear velocity of $50 \mathrm{~m} / \mathrm{s}$, it is formed at a low shear strain of $0.04 \%$. The shear strain - moment diagram proposed in this study provide a simple yet robust method to evaluate the seismic performance of cut-and-cover box tunnels under seismic loading.

\section{REFERENCES}

1) Androtti G., Lai G. C, Martinelli M. (2013): Seismic fragility functions of deep tunnels: A new cumulative damage model based on lumped plasticity and rotation capacity, ICEGE Istanbul, Turkey.

2) Argyroudis S. A., Pitilakis K. D. (2012): Seismic fragility curves of shallow tunnels in alluvial deposit, Soil Dynamics and Earthquake Engineering, 35, 1-12.

3) FEMA 356 (2000): Prestandard and Commentary for the Seismic Rehabilitation of Buildings, ASCE.

4) Hashash Y. Hook J. J., Schmidt B. (2001): Seismic design and analysis of underground structure. Tunnel and Underground Space Technology 16, 247-293.

5) Pitilakis K. and Tsinidis G. (2014): Chapter 11 Performance and Seismic Design of Underground Structures. Earthquake Geotechnical Engineering Design, Springer International Publishing Switzerland.

6) Argyroudis S. and Kaynia A. M. (2014): Fragility functions of Highway and Railway Infrastructure, Chapter 10 of SYNER-G: Typology Definition and Fragility Functions for Physical Elements at Seismic Risk Springer Netherlands, 299-326.
7) Wang J. N. (1993): Seismic Design of Tunnels, A simple State-of-Art Design Approach.

8) Wood J. H. (2004): Earthquake design procedures for rectangular underground structures. EQC Project No 01/470.

9) Wang Z. Z., Zhang Z. (2013): Seismic damage classification and risk assessment of mountain tunnels with a validation for 2008 Wenchuan earthquake. Soil Dynamic and Earthquake Engineering, 45, 45-55. 